\title{
Factors of yield resilience under changing weather evidenced by a 14-year record of corn-hay yield in a 1000-cow dairy farm
}

\author{
Emmaline A. Long ${ }^{1}$ - Quirine M. Ketterings ${ }^{2}$
}

Accepted: 4 January 2016 / Published online: 22 February 2016

(C) INRA and Springer-Verlag France 2016

\begin{abstract}
Dairy farms can improve their environmental footprint by feeding more homegrown forage. As a consequence, higher yields will reduce feed imports and enhance nutrient use efficiency. To improve forage production, limitations to production need to be identified. In particular, there is a need for long-term yield records, of at least 8 years, to evaluate yield stability and production trends. Such information should allow us to identify the system with the best buffering capacity (resilience) under changing climate. Here, we analyzed 14 years of yield data from a 1000-cow dairy farm. We studied individual field yield and farm-average yields of corn silage and alfalfa and grass hay mixtures. Fields were classified in four quadrants based on yield and yield variability over time. Soil physical and chemical properties were evaluated as potential indicators of biological buffering capacity. Across all fields, corn silage yield increased from 13.3 to $17.8 \mathrm{Mg}$ dry matter (DM) $\mathrm{ha}^{-1}$ between 2000 and 2013 whereas hay yield averaged 8.6 $\mathrm{Mg} \mathrm{DM} \mathrm{ha}^{-1}$ without a trend. Those findings are explained by timing and amount of rainfall, field drainage, soil phosphorus, and organic matter. Fields with the highest biological buffering capacity averaged 18-20 mg Morgan soil test phosphorus $\mathrm{kg}^{-1}$ and $2.9-3.2 \%$ organic matter versus $9 \mathrm{mg}$ phosphorus $\mathrm{kg}^{-1}$ and $2.7-2.8 \%$ organic matter for low and variableyielding fields. We suggest therefore that management
\end{abstract}

Quirine M. Ketterings

qmk2@cornell.edu

Emmaline A. Long

Ea193@cornell.edu

1 Animal Science Department, Nutrient Management Spear Program, Cornell University, 319 Morrison Hall, Ithaca, NY 14853, USA

2 Animal Science Department, Nutrient Management Spear Program, Cornell University, 323 Morrison Hall, Ithaca, NY 14853, USA practices that increase organic matter, improve drainage, and provide optimal soil fertility will result in higher and more stable yields that are less impacted by weather extremes.

Keywords Corn silage $\cdot$ Alfalfa $\cdot$ Forage $\cdot$ Yield $\cdot$ Variability Phosphorus · Organic matter

$\begin{array}{ll}\text { Abbreviations } \\ \text { BBC } & \text { Biological Buffering Capacity } \\ \mathrm{Ca} & \text { Calcium } \\ \mathrm{CSNT} & \text { Corn Stalk Nitrate Test } \\ \mathrm{CV} & \text { Coefficient of Variation } \\ \mathrm{DM} & \text { Dry matter } \\ \mathrm{K} & \text { Potassium } \\ \mathrm{Mg} & \text { Magnesium } \\ \mathrm{NRCS} & \text { Natural Resources Conservation Service } \\ \mathrm{N} & \text { Nitrogen } \\ \mathrm{NY} & \text { New York } \\ \mathrm{P} & \text { Phosphorus } \\ \mathrm{OM} & \text { Organic matter }\end{array}$

\section{Introduction}

New York (NY) is ranked fourth in the nation for milk production and third for corn silage production (National Agricultural Statistics Service 2013). In the past 10 years, the proportion of forages as a percent of the total ration dry matter (DM) in Northeast dairy farm rations has increased from less than $50 \%$ of the total DM to 55-70 \% forage as a percent of the total ration DM (Chase and Grant 2013). Assessments of 102 NY dairy farms in 2006 showed that nearly all the forages fed were produced on the farm (homegrown forages) reducing the farm's cost of production and environmental footprint and increasing 
its whole-farm nutrient use efficiency (Cela et al. 2014). The predominant forages grown for dairy cow rations in $\mathrm{NY}$ are corn (Zea mays L.) silage and alfalfa (Medicago sativa L.) and grass hay mixtures. Statewide average corn silage yields have increased from $10.8 \mathrm{Mg} \mathrm{ha}^{-1}$ in 2002 to $13.3 \mathrm{Mg} \mathrm{ha}^{-1}$ in 2013. Alfalfa/grass hay average yield has stayed consistent from 2002 to 2013 at $6.7 \mathrm{Mg} \mathrm{ha}^{-1}$ (National Agricultural Statistics Service 2013).

To identify limitations to crop production on individual farms or fields and to improve field and farm productivity over time, accurate yield records are essential. Recognizing the need for outcome-based approaches to managing nutrients on farms, the Natural Resources Conservation Service (NRCS) released a new Nutrient Management Conservation Practice Standard Code 590 in 2013. This new standard allows farms to use "adaptive management practices" that include assessments of crop yield response to management alternatives (NRCS 2013). In NY, the standard refers to Landgrant University guidelines which, for nitrogen $(\mathrm{N})$ management, now state that farmers can determine $\mathrm{N}$ application practices for corn based on the following: (1) soil type specific corn yield potentials as documented in the Cornell University yield and soil database (Ketterings et al. 2003a); (2) 3 years of actual corn yield records; (3) findings of 2 years of on-farm replicated trials with a minimum of four replications and five $\mathrm{N}$ rates including a zero- $\mathrm{N}$ control treatment; or (4) yield measurements and corn stalk nitrate test (CSNT) results (Ketterings et al. 2013). The latter is a recent adaptive management strategy that allows farmers to override the Cornell University yield database without evidence of higher yields, as long as yields are documented and CSNTs are managed below $3000 \mathrm{mg} \mathrm{kg}^{-1}$ for each year in which this strategy is used (Ketterings et al. 2013). This adaptive management approach allows for continued adjustments to field management practices to achieve better nutrient use efficiency and yields over time.

In addition to being an essential component of adaptive management, yield records are also essential for evaluation of management alternatives through on-farm research, an important tool for fine-tuning of management over time. As an example, Ketterings et al. (2013) reported a significant reduction in starter $\mathrm{N}$ fertilizer at a western $\mathrm{NY}$ concentrated animal feeding operation (CAFO) following 2 years of replicated trials that showed no crop yield or quality response to starter $\mathrm{N}$ applications at the time of corn planting. Similarly, a large statewide project that included on-farm research trials showed that corn could be grown without starter phosphorus (P) fertilizer for fields testing optimal or excessive in soil test $\mathrm{P}$ (Ketterings et al. 2005) resulting in drastic decrease in P starter use in NY (Ketterings et al. 2011).

Soil, crop, and weather interactions over time impact both yield and nutrient supply and demand, specifically for $\mathrm{N}$. Soil-plant nutrient resiliency has been documented by a number of researchers in the past 20 years (Fox and Kiekielek 1995; Schlegel et al. 1996; Vanotti and Bundy 1994). Meisinger et al. (2008) introduced the term biological buffering capacity (BBC) as a more encompassing name for soil-plant nutrient resiliency to describe a soil's and plant's ability to adjust to changes in weather. Biological buffering capacity is based on the assumption that crop yield and nutrient uptake reflect closely linked soil-crop interactions that are affected by growing-season weather (Meisinger et al. 2008). A field with high BBC will have greater soil health and be more consistent in its need for external fertilization to reach yield potential; these fields will likely be more stable in yield from year to year, somewhat independent of weather. A field with a low BBC will vary in optimum fertilizer rates from year to year as it will not be able to supply the additional nutrients in high-yielding years. These fields will likely show greater yield difference between high- and low-yielding weather years as well. Evaluation of long-term forage yield records can aid in identification of fields or areas within fields that have a high BBC. Further evaluation of the characteristics of those fields (soil fertility and soil health, crop rotation, management histories, etc.) and their interactions will increase our scientific understanding of drivers of $\mathrm{BBC}$ and aid in development of best management practices that can increase yields for lowyielding fields and reduce the environmental footprint of the farming operations. A systematic approach is needed that allows for assessment of BBC based on yield data at the whole farm, field by field, and within-field levels.

Until the introduction of forage yield monitors, the only accurate way to determine whole-farm crop yields was with the use of farm scales (Fig. 1) combined with estimations of forage moisture obtained using microwave ovens or Koster testers (Koster Moisture Testers: Brunswick, OH, USA). Portable axel truck scales can be used as well, but use of such scales (1) introduces greater error in yield estimates as typically not all axels can be weighed simultaneously and (2) slows down the harvest process. In contrast, driving trucks over permanent farm scales located close to the bunks causes minimal delay. Thus, few farms have long-term forage yield records. One exception is a western NY CAFO-sized dairy farm where all truck-loads of all corn and hay fields have been weighed and recorded throughout the past 14 years to evaluate field-level and whole-farm yields as part of the farm's quest to identify barriers to higher and more stable yield levels.

The overall objectives of this study were to (1) determine the temporal variability of forage yields (corn silage, alfalfa/ grass hay, and overall DM production) on a NY dairy farm over 14 crop years, (2) assess yield and yield stability over time across all fields with at least two crop rotations, and (3) evaluate soil physical and chemical properties as potential indicators of yield and yield stability over time. 


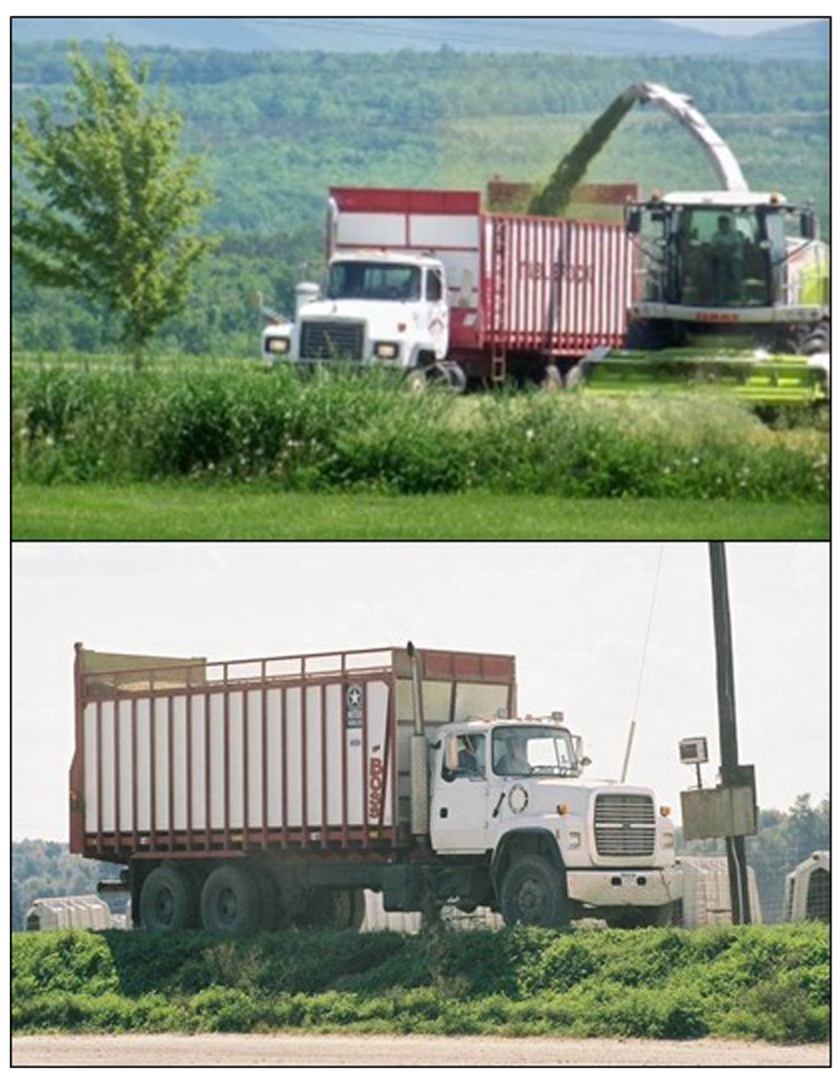

Fig. 1 Photograph of harvesting an alfalfa/grass crop on the case study farm using a self-propelled forage harvester (top). A truck weighing a load of silage to determine yield (bottom). Both photos demonstrate parts of the farm's forage yield documentation process

\section{Materials and methods}

\subsection{Study site and management practices}

The yield evaluations were done using data from a 1000-cow dairy farm in Wyoming County, NY, that farmed 730 tillable hectares of land, including 360 ha of corn silage and 315 ha of alfalfa/grass mixtures, with the remainder of land in corn grain or vegetable production. The farm's typical crop rotation was 3 years of corn silage followed by 3 years of an alfalfa/grass hay mixture. Alfalfa/grass hay was harvested as haylage and averaged four cuttings per year. On fields that were planted to corn, manure was typically injected in the spring, followed by tillage (zone building and seedbed preparation using an aerator), and planting. The farm has used reduced tillage practices since 2000. Corn was planted in rows spaced $38 \mathrm{~cm}$ apart. Liquid manure from the dairy has been applied to the soil via injection since 1994. Manure was the only fertilizer nutrient source on this farm from 2007 onwards (Ketterings 2014). The farm seeds winter cereals as cover crops annually on as many corn silage acres as possible (weather determined). Cover crops are typically seeded with manure application in the fall.

\subsection{Yield data}

Yield was measured from 2000 through 2013, with the exception of 2006 when harvest data for corn were lost. Yield was recorded each year for a total of 107 fields ranging in size from 1.0 to $26.5 \mathrm{ha}$. The records included harvested area, crop grown, and DM yield for each field. Dry matter was calculated for both crops using a Koster tester (Koster Moisture Tester Inc., Brunswick, OH, USA) and averaged across each field. Moisture was calculated for each cutting of alfalfa and corrected to $100 \%$ DM. Corn silage moisture was corrected to $30 \% \mathrm{DM}$. Yield was calculated using the sum of the weight of all loads for each field determined with a farm scale that was located near the bunk silo (Fig. 1). For each year, areaweighted mean DM yield of each crop was calculated to determine whole-farm (corn silage and alfalfa/grass hay) yield.

\subsection{Soil data}

Soil physical properties for each field included soil series (Wulforst et al. 1974), hydrologic group (Ketterings et al. 2003a), drainage class (Soil Survey Division Staff 1993), and soil management group (Cornell Cooperative Cornell Cooperative Extension 2013). The soil series used in analysis was the predominant ( $>50 \%$ of the field) soil series represented in the field. The hydrologic groups included the following: (1) deep, well-drained sands and gravels (group A soils); (2) moderately drained with moderately fine to moderately coarse texture (group B soils); (3) impeding layer present, finetexture (group C soils); and (4) clay soils and soils with a high water table (group D soils) (Ketterings et al. 2003a). The drainage classes represented included moderately welldrained (M), somewhat well-drained (S), and well-drained (W) (Soil Survey Division Staff 1993). Soil management groups present on the farm included the following: (2) medium- to fine-textured soils developed from calcareous glacial till and medium-textured to moderately fine-textured soils developed from slightly calcareous glacial till mixed with shale and medium-textured soils developed in recent alluvium; and (3) moderately coarse-textured soil developed from glacial outwash and recent alluvium and medium-textured acid soil developed on glacial till (Cornell Cooperative Cornell Cooperative Extension 2013).

Soil sampling of each field was conducted based on the NRCS Nutrient Management Conservation Practice Standard Code 590 (NRCS 2013). The farm consultant sampled approximately one third of the farm's acreage annually. Chemical properties included soil organic matter $(\mathrm{OM}), \mathrm{pH}, \mathrm{P}$, potassium $(\mathrm{K})$, calcium $(\mathrm{Ca})$, and magnesium $(\mathrm{Mg})$. Analyses were conducted by Spectrum Analytic Inc. (Washington Court House, $\mathrm{OH})$. Organic matter and $\mathrm{pH}(1: 1(w: v)$ water extract) were analyzed using methods as described by Storer (1984), with the $\mathrm{OM}$ method adapted to $360^{\circ} \mathrm{C}$ for $2 \mathrm{~h}$ as described in 
Schulte and Hoskins (1995). Phosphorus, K, Ca, and $\mathrm{Mg}$ were analyzed by Spectrum Analytic (Washington Court House, $\mathrm{OH}$ ) using the Mehlich-3 extraction as outlined in Wolf and Beegle (1995). Mehlich-3 P values were converted to Cornell University Morgan-P equivalents based on Ketterings et al. (2002), and Morgan-P results were classified as low, medium, high, or very high according to Cornell University guidelines for field crops as documented in Ketterings et al. (2003b).

\subsection{Temporal variability of forage yields}

Trends in annual weighted mean DM yields (corn silage, alfalfa/grass hay, and total yearly production) were analyzed using simple linear regression. Annual climate data included rainfall and growing degree days obtained from the Climate Information for Management and Operational Decisions (CLIMOD 2014). These data were used to evaluate the impact of weather on trends in yield over time; analyses were done for March to October (full growing season), March to April (corn planting season), and July to August (corn tasseling window). For alfalfa/grass hay cuttings, monthly weather data were analyzed for their impact on yield. Simple linear regression was used to compare the amount of rainfall during each of the periods to the mean yield.

\subsection{Spatial variability of forage yields}

Spatial variability was determined using 107 fields with two or more rotations of data. Of those fields, 61 fields had six corn years each and 71 fields had five full production years for alfalfa/grass hay. The mean yield and coefficient of variation (CV) were calculated for each field. The fields were divided into four quadrants (Q1-Q4), using the overall weighted mean yield and mean $\mathrm{CV}$ as cutoffs for the quadrants: (1) above mean yield, below mean CV (Q1); (2) above mean yield, above mean CV (Q2); (3) below mean yield, above mean CV (Q3); and (4) below mean yield, below mean CV (Q4). Fields in Q1 were consistently high-yielding fields with high biological buffering capacity. Mean yield and CV were calculated for each quadrant, and significant differences among quadrants were determined using Tukey's least significant difference $(p \leq 0.05)$ in JMP Version 10 (SAS Institute 2012). Significant differences among quadrants were determined for physical (hydrologic group, drainage class, and soil management group) and chemical (OM, pH, available $\mathrm{P}, \mathrm{K}, \mathrm{Ca}, \mathrm{Mg}$ ) soil properties. Comparisons in soil chemical properties were conducted using the most recent soil test for each field to reflect crop yield history, crop rotation, nutrient balances, and manure history throughout the time period of the study.
A linear-plus-plateau model was run in Graph Pad Prism Version 6 (GraphPad and Inc 2014) to determine the correlation of yield to soil test P. The linear-plus-plateau model is defined by Eqs. 1 and 2:

$\mathrm{Y}=\mathrm{a}+\mathrm{bX}$ if $\mathrm{X}<\mathrm{C}$

$\mathrm{Y}=\mathrm{Z}$ if $\mathrm{X} \geq \mathrm{C}$

where $\mathrm{Y}$ is the forage yield $\left(\mathrm{Mg} \mathrm{DM} \mathrm{ha}{ }^{-1}\right), \mathrm{X}$ is the Cornell University Morgan-P equivalent ( $\mathrm{mg} \mathrm{P} \mathrm{kg}^{-1}$ ); a is the intercept, $\mathrm{b}$ is the slope, $\mathrm{C}$ is the critical soil test $\mathrm{P}$, and $\mathrm{Z}$ is the plateau yield.

\section{Results and discussion}

\subsection{Trends in forage yields over time}

Overall corn yield increased from $13.3 \mathrm{Mg} \mathrm{DM} \mathrm{ha}{ }^{-1}$ in 2000 to $17.8 \mathrm{Mg} \mathrm{DM} \mathrm{ha}{ }^{-1}$ in 2013 (Fig. 2) and ranged, among fields, from 14.1 to $21.1 \mathrm{Mg} \mathrm{DM} \mathrm{ha}{ }^{-1}$ in 2013 . The $25 \%$ increase over time is consistent with the $20 \%$ increase in NY corn silage yield from 2002 to 2013 reported by the National Agricultural Statistics Service (2015). Alfalfa/grass hay DM yield did not increase over the same time period, averaging $8.6 \pm 1.4 \mathrm{Mg} \mathrm{DM} \mathrm{ha}{ }^{-1}$ with a range among fields from 7.5 to $13.4 \mathrm{Mg} \mathrm{DM}$ $\mathrm{ha}^{-1}$ in 2013. The corn silage and alfalfa/grass hay yields in 2013 on the case study farm were 37 and $22 \%$ higher than the state average that year. Across all fields and years, on-farm DM production increased from $11.6 \mathrm{Mg}$ $\mathrm{DM} \mathrm{ha}^{-1}$ in 2000 to $13.5 \mathrm{Mg} \mathrm{DM} \mathrm{ha}^{-1}$ in 2013 , reflecting primarily the increase in corn silage yield over time. The significant corn silage yield increase is representative of the extensive breeding and research going into developing new, highly productive corn varieties at a very quick pace (Edgerton 2009). Comparatively, alfalfa breeding has focused more on nutritional value and ruminant digestion, rather than increased yields (Lamb et al. 2006). Additionally, in a typical corn and alfalfa/grass hay rotation for the farm (3 years of corn and 3 years of alfalfa/ grass hay), alfalfa varieties can only be changed once in 6 years.

Growing degree days since planting and whole-season (March through October) rainfall did not impact corn or alfalfa/grass hay yield. Corn silage yield was, however, impacted by rainfall during March and April and during July and August. An increase in rainfall during March and April, just prior to corn planting, caused a decrease in overall yield $(p=0.0168)$. In contrast, an increase in rainfall during July and August, a time period in which tasseling occurs, was correlated with an increase in overall yield $(p=0.0262)$ (Fig. 2). Alfalfa/grass hay yield was not correlated with 


\section{Mean Yield}

(Mg DM ha-1)
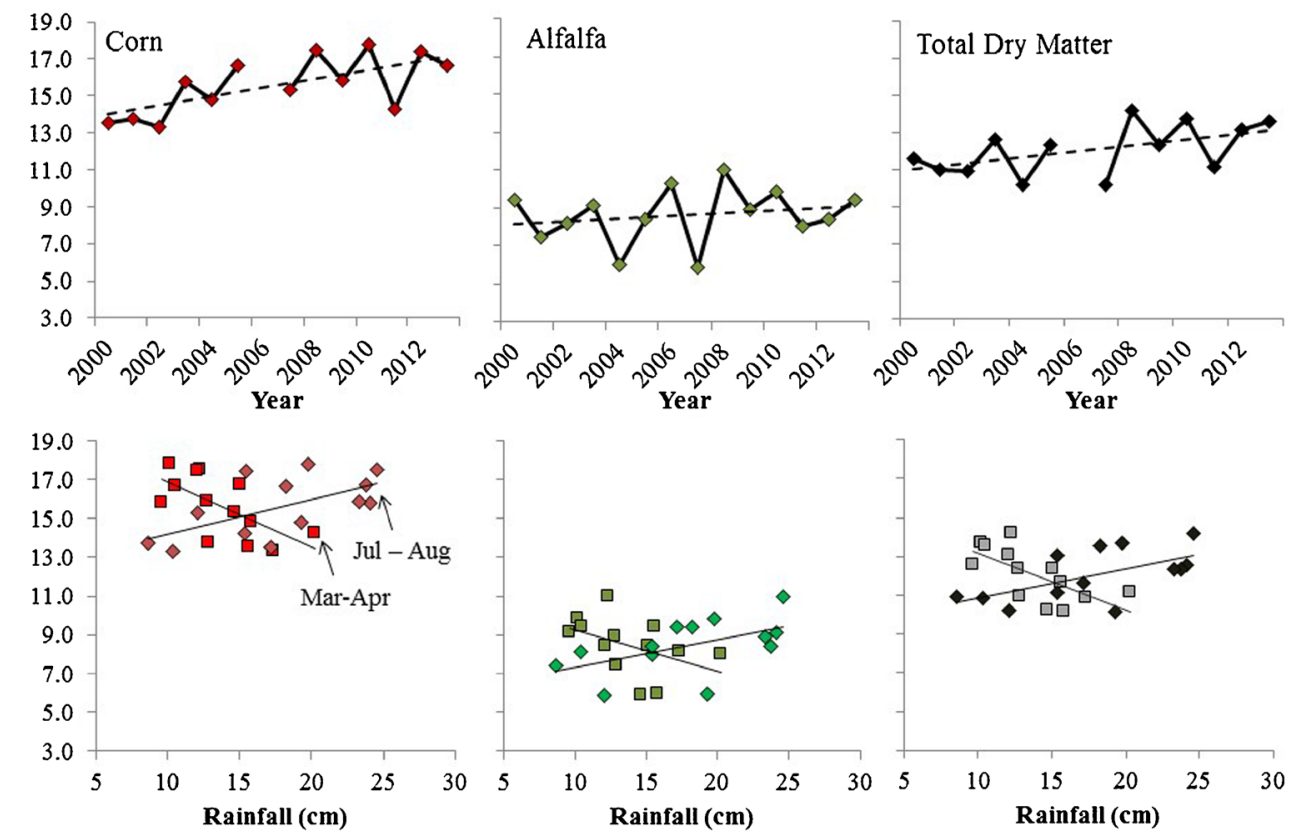

Fig. 2 Yield trends of corn, alfalfa/grass hay, and total dry matter production on a western New York farm from 2000 to 2013 as impacted by rainfall during March-April and July-August. Corn silage yield increased during the time period $\left(R^{2}=0.47^{* *}, p\right.$ value $\left.=0.01\right)$. The corn silage regression was yield $=-480.75+0.25 *$ year. Alfalfa/grass yield remained constant $\left(R^{2}=0.04, p\right.$ value $\left.=0.50\right)$. Total dry matter production also increased $\left(R^{2}=0.27^{*}, p\right.$ value $\left.=0.07\right)$. The dry matter regression was yield $=-304.28+0.16^{*}$ year. Corn yield was impacted by rainfall during planting (March through April, yield $=20.19-0.33^{*}$

rainfall, $R^{2}=0.20, p$ value $=0.02$ ) and tasseling (July through August, yield $=12.36+0.18 *$ rainfall, $R^{2}=0.37, p$ value $=0.03$ ). Alfalfa yield was impacted by rainfall during July through August (yield $=5.9+$ $0.14 *$ rainfall, $R^{2}=0.28, p$ value $=0.06$ ). Total dry matter was impacted by both March through April rainfall (yield $=16.14-0.30 *$ rainfall, $R^{2}=0.46, p$ value $\left.=0.01\right)$ and July through August rainfall (yield $=9.40+0.15 *$ rainfall, $R^{2}=0.36, p$ value $=0.03$ ). The single asterisk symbol indicates significance at $p \leq 0.10$ and double asterisk symbol indicates significance at $p \leq 0.05$

Fig. 3 Average yield of corn silage (a) and alfalfa/grass hay (b) and coefficient of variation for each field on a western New York farm with two full rotations of yield data. Dotted lines represent the overall average yield and coefficient of variation. Quadrants are labeled 1-4 and identify those fields which are high or low yielding and exhibit high or low variability. Fields with the highest biological buffering capacity are in Q1

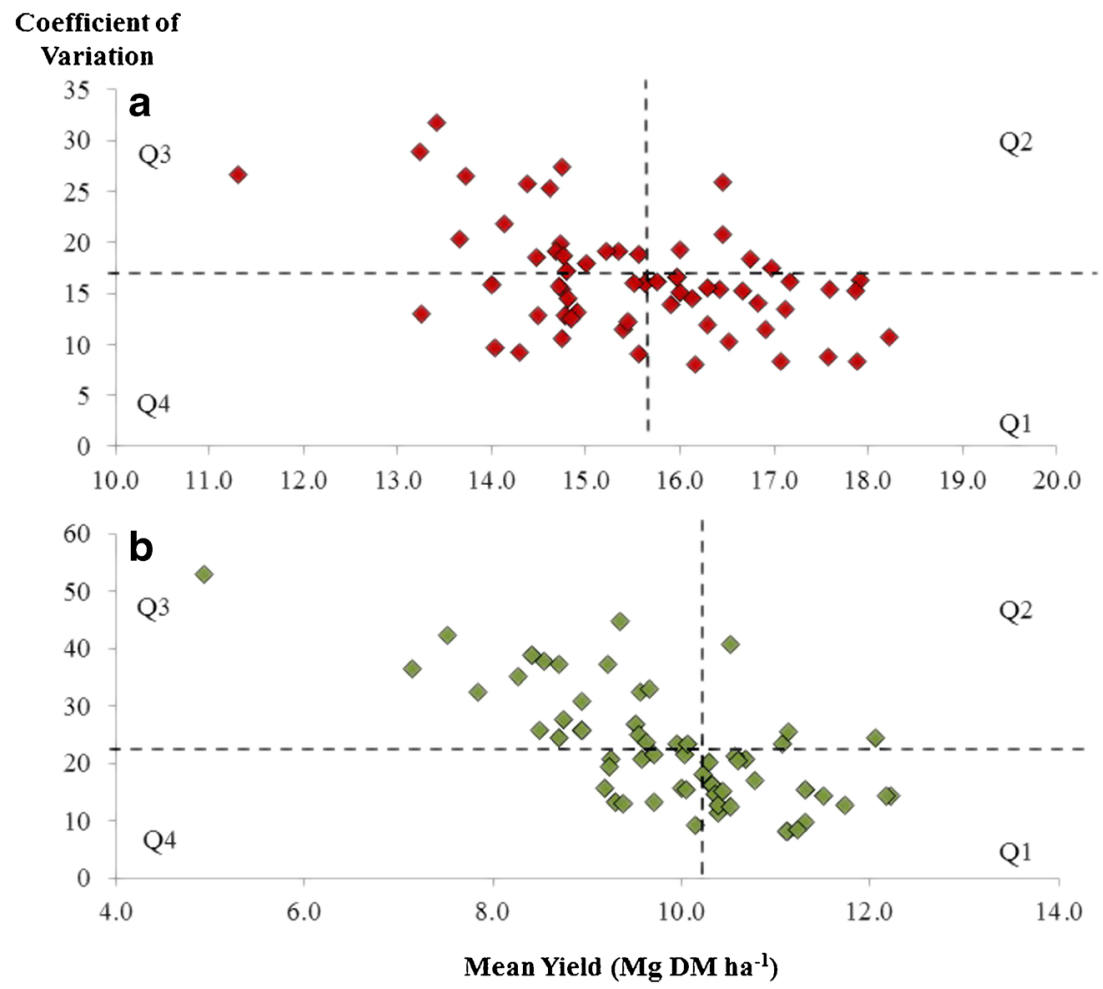




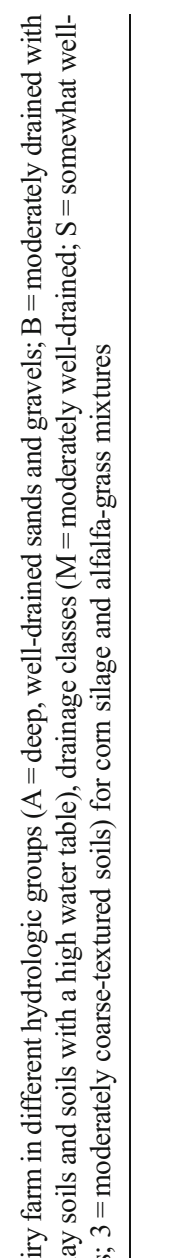

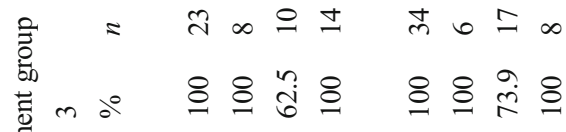

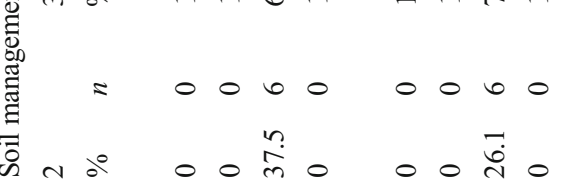

$$
\begin{aligned}
& =\stackrel{\infty}{=}+\infty \quad \stackrel{i}{*} \stackrel{\circ}{=}
\end{aligned}
$$

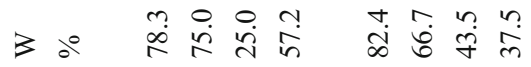
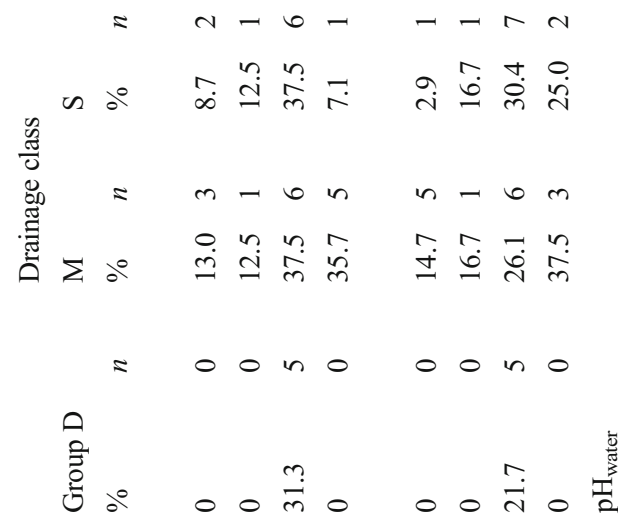

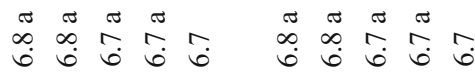

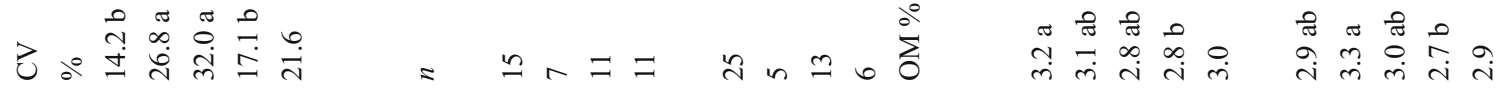

竞

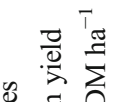

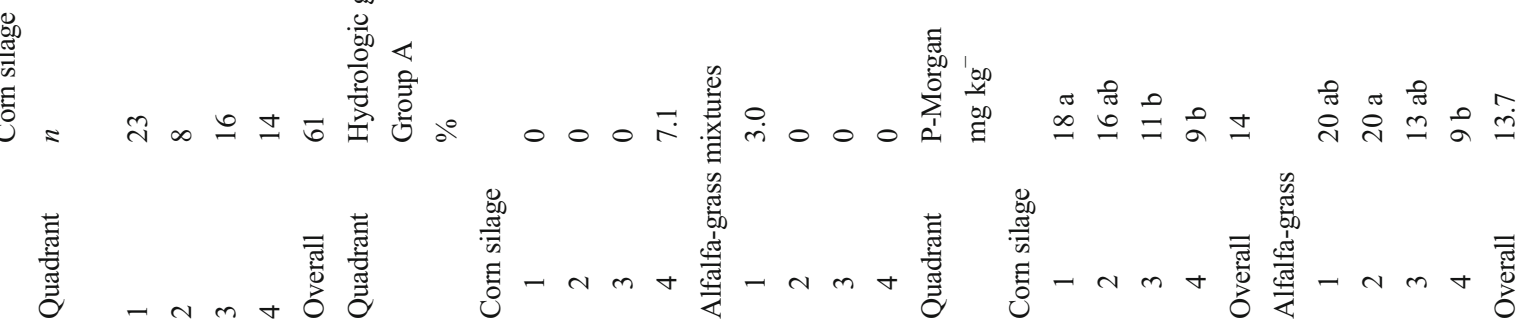




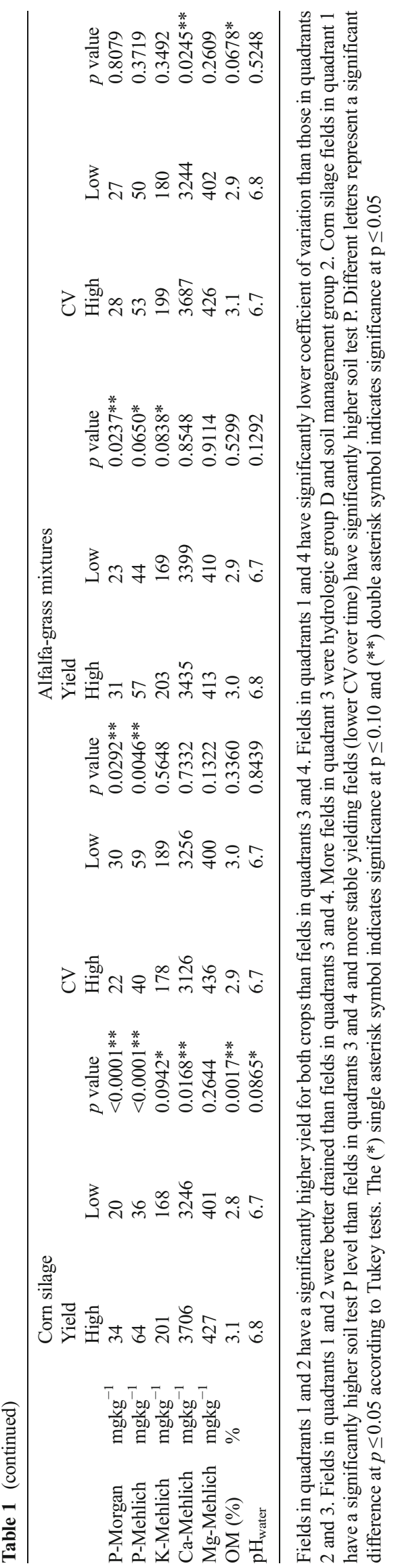

rainfall during individual months (data not shown), but increased with total rainfall in July and August $(p=0.0607)$ (Fig. 2). Whole-season (March through October) rainfall did not impact the overall alfalfa/grass hay yield, but total DM yield was impacted by rainfall during March and April $(p=0.0105)$ and July and August $(p=0.0262)$ reflecting a positive correlation in corn silage yield.

\subsection{Field to field variability in yield and yield stability}

Corn silage average yield across fields and years was 15.6 $\mathrm{Mg} \mathrm{ha}{ }^{-1}$, with a mean $\mathrm{CV}$ of $16.4 \%$ (Fig. 3a, Table 1). In contrast, the overall yield for alfalfa/grass hay was $9.9 \mathrm{Mg} \mathrm{ha}^{-1}$, with a mean $\mathrm{CV}$ of $21.6 \%$ (Fig. 3b, Table 1). For corn and alfalfa/grass hay fields yielding above the farm average, there was 74 and $86 \%$ probability of a CV below the farm average, respectively, indicating that the higher yielding fields tend to be more consistent in yield over time (higher BBC) than below average yielding fields.

The soils in Q1 and Q2 had a higher percentage of well-drained soils versus primarily moderately and somewhat well-drained soils for Q3 and Q4, consistent with yield potentials for the better-drained soils (Ketterings et al. 2003b). However, it should be noted that fields were characterized by their predominant soil type within the field. Other soil types present within individual fields can impact yield and yield stability, and soil chemical properties also should be considered when quantifying spatial variability.

Soils in the four quadrants did not differ in extractable K, $\mathrm{Mg}$, or $\mathrm{pH}$ (Table 1). Extractable calcium was significantly higher in Q1 than Q4 for corn silage, while Q2 and Q3 had significantly higher $\mathrm{Ca}$ levels than $\mathrm{Q} 4$ for alfalfa/grass hay fields. Calcium levels are, however, not a crop growth limitation for corn and alfalfa/grass in NY (Cornell Cooperative Cornell Cooperative Extension 2013).

In corn silage fields, OM levels were significantly higher in Q1 than in Q4, suggesting a correlation between $\mathrm{OM}$ and yield. For alfalfa/grass hay fields, Q2 had a significantly higher OM level than Q4, again suggesting higher OM supports higher yields. Organic matter for the fields with the highest BBC averaged 2.9 and $3.2 \%$ for corn silage and alfalfa/grass hay, respectively, versus 2.7 and $2.8 \% \mathrm{OM}$ for low and variable yielding fields. Such observations point the need to include an estimate of $\mathrm{OM}$ and $\mathrm{N}$ mineralization in $\mathrm{N}$ recommendation systems, as detailed by Meisinger et al. (2008). Consistently high-yielding fields averaged 18 and $20 \mathrm{Mg} \mathrm{kg}^{-1}$ Morgan soil test $\mathrm{P}$ for corn silage and alfalfa/grass hay, respectively, versus $9 \mathrm{Mg} \mathrm{kg}^{-1}$ Morgan soil test $\mathrm{P}$ for low-yielding and more variable fields (Table 1). High-yielding corn silage fields also 
had higher extractable $\mathrm{K}, \mathrm{Ca}$, and more $\mathrm{OM}$, which likely reflect a longer and more recent manure history for these fields (Table 1). There was a significant difference in $\mathrm{pH}$ among high- and low-yielding corn silage fields, but the difference was too small to be of biological significance. Corn silage fields with a below average CV (less variable over time) had higher mean soil test $\mathrm{P}$ than those with a higher than average $\mathrm{CV}$. High-yielding alfalfa/grass hay fields had higher soil test $\mathrm{P}$ and $\mathrm{K}$ than low-yielding fields, which again could be indicative of a more extensive manure history. Alfalfa/grass hay fields with a lower CV had significantly higher $\mathrm{Ca}$ and $\mathrm{OM}$ as well, consistent with the findings for the corn fields, and consistent with a corn and alfalfa/grass rotation.

Across all fields for both crops, yield increased as soil test $\mathrm{P}$ increased up to $16.1 \mathrm{mg} \mathrm{kg}{ }^{-1}$ for corn silage and $14.6 \mathrm{mg} \mathrm{kg}^{-1}$ for alfalfa/grass hay (Fig. 4). There was no relation between average yield and soil test $\mathrm{P}$ at higher soil test levels. These results support previous findings in NY which showed when a field has a soil test $\mathrm{P}$ greater than $10 \mathrm{mg} \mathrm{kg}^{-1}$, $\mathrm{P}$ fertilizer addition did not increase yield (Ketterings et al. 2005). Of the corn fields included in this study, $68 \%$ had high or very high soil test $\mathrm{P}$, where $\mathrm{P}$ fertilizer addition is not recommended (Ketterings et al. 2003b).

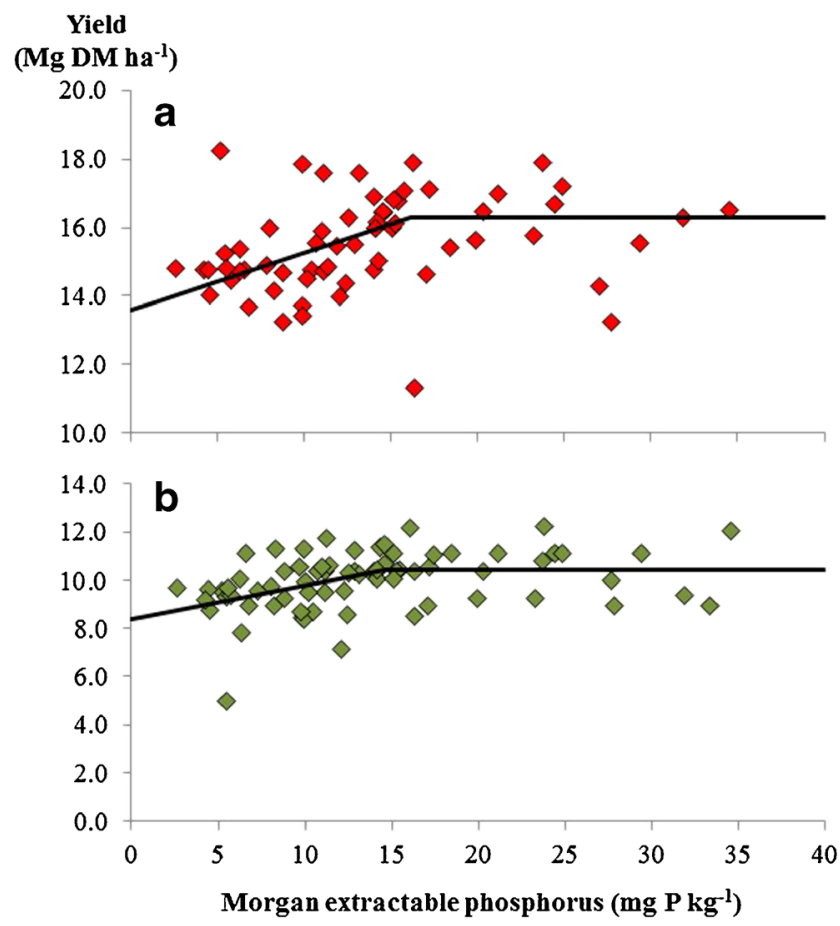

Fig. 4 Yield of corn silage and alfalfa/grass hay on a western New York farm, as impacted by Morgan extractable phosphorus soil test levels. As soil test phosphorus increases, the yield increased until approximately $16.1 \mathrm{mg} \mathrm{kg}^{-1}$ for corn silage and $14.6 \mathrm{mg} \mathrm{kg}^{-1}$ for alfalfa/grass

\subsection{Implications}

The quadrant method presented here was used to identify fields based on whole-field yield averages for a minimum of two cycles in a rotation. As mentioned, very few dairy farms have such data for forage production. With the increasing availability of forage yield monitors (Digman and Shinners 2012; Long et al. 2016; McBratney et al. 2005), within-field variability in yield can be documented and geo-referenced. The quadrant method presented here is a novel approach that can be applied at the field scale and at a within-field scale. When combined with precision agriculture that allows for within-field management (such as variable rate planting, fertilizer and manure addition), the quadrant approach can aid in the identification of variable rate best management practices that increase overall field and farm yield and nutrient use efficiency. Such within-field management is essential to improving whole-farm productivity and crop management while reducing agriculture's environmental footprint.

\section{Conclusions}

On this case study farm, overall DM yield was impacted by the annual growing conditions, specifically the amount of rainfall in March-April and July-August, which are critical times for planting and growth of corn silage and alfalfa/grass hay crops. Yet, some fields were consistently high yielding (high $\mathrm{BBC}$ ) while others were low-yielding or variable. The highest and most consistently yielding fields had better-drained soils, were classified as optimum or high in soil test $\mathrm{P}$, and were higher in $\mathrm{OM}$ than the lower yielding and more variable fields. Farmer practices that improve soil drainage (tile drainage), conserve or even increase organic matter (reduced tillage and cover crops), and enhance soil test $\mathrm{P}$ (manure application) to optimal levels will increase the overall corn silage yield. Separating fields into quadrants based on yield and CV over time helps to identify fields that have greater soil health and BBC. This approach allows for identification of fields, or areas within fields, with higher $\mathrm{BBC}$ and drivers of $\mathrm{BBC}$ can aid in the development of best management practices that increase yields and reduce the environmental footprint of the farming operations.

Acknowledgments The authors would like to thank Willard DeGolyer and Meghan Hauser of Table Rock Farm for generously sharing their yield data and field histories with us for this project, as well as their time in helping us with conclusions. This work was supported by a Northeast Sustainable Agriculture Research and Education grant (NESARE GNE12-039) and a USDA-NRCS-Conservation Innovation Grant (USDA-NRCS CIG 69-2C31-1-205). 


\section{References}

Cela S, Ketterings QM, Czymmek KJ, Soberon M, Rasmussen C (2014) Characterization of nitrogen, phosphorus, and potassium mass balances in dairy farms in New York State. J Dairy Sci 97:1-19. doi:10. 3168/jds.2014-8467

Chase LE, Grant RJ (2013) High forage rations - What do we know? In: Proceedings of the 2013 Cornell Nutrition Conference for Feed manufacturers. Cornell University, New York, pp. 203-209

CLIMOD (2014) Ithaca, NY: Northeast Regional Climate Center

Cornell Cooperative Extension (2013) 2014 Cornell guide for integrated field crop management. Cornell University, Ithaca

Digman, MF, Shinners KJ (2012) Technology Background and Best Practices: Yield mapping in hay and forage. In Proceedings of the 42nd California Alfalfa and Grains Symposium, December 10-12, Sacramento, pp 138-143

Edgerton MD (2009) Increasing crop productivity to meet global needs for feed, food and fuel. Plant Physiol 149:7-13. doi:10.1104/pp.108. 130195

Fox RH, Kiekielek WP (1995) The relationship between corn grain yield goals and economically optimum nitrogen fertilizer rates. Agron. Se. 136. Penn State Univ, University Park

GraphPad Software, Inc. (2014) GraphPad Prism 6.0. La Jolla, CA

Ketterings QM (2014) Extension and knowledge transfer: adaptive management approaches for timely impact. J Agr Sci. doi:10.1017/ S002185961300066X

Ketterings QM, Czymmek KJ, Reid WS, Wildman RF (2002) Conversion of modified Morgan and Mehlich-III soil tests to Morgan soil test values. Soil Sci 167:830-837. doi:10.1097/01.ss. 0000043031.06837.d3

Ketterings QM, Klausner SD, Czymmek KJ (2003a) Nitrogen guidelines for field crops in New York. CSS extension series E03-16. Cornell University, Department of Crop and Soil Sciences, Ithaca

Ketterings QM, Klausner SD, Czymmek KJ (2003b) Phosphorus guidelines for field crops in New York. CSS extension series E03-15. Cornell University, Department of Crop and Soil Sciences, Ithaca

Ketterings QM, Swink SM, Godwin G, Czymmek KJ, Albrecht GL (2005) Maize silage yield and quality response to starter phosphorus fertilizer in high phosphorus soils in New York. J Food Agric Environ 3:237-242

Ketterings QM, Czymmek KJ, Swink SN (2011) Evaluation methods for a combined research and extension program used to address starter phosphorus fertilizer use for corn in New York. Can J Soil Sci 91: 467-477. doi:10.4141/cjss 10001

Ketterings QM, Czymmek KJ, Albrecht G, Gates D, \& Lendrum J (2013) Nitrogen for corn; management options. Agron. Fact Sheet 77.
Cornell Univ. Coop. Ext., Ithaca. http://nmsp.cals.cornell.edu/ publications/factsheets/factsheet77.pdf. Accessed 15 July 2014

Lamb JFS, Sheaffer CC, Rhodes LH, Sulc RM, Undersander DJ, Brummer EC (2006) Five decades of alfalfa cultivar improvement: impact on forage yield, persistence, and nutritive value. Crop Sci 46: 902-909. doi:10.2135/cropsci2005.08-0236

Long EL, Ketterings QM, Russell D, Vermeylen F (2016) Assessment of yield monitoring equipment for dry matter and yield of corn silage and alfalfa/grass. Precision Ag. doi:10.1007/ s11119-016-9436-y

McBratney A, Whelan B, Ancev T (2005) Future directions of precision agriculture. Precision Ag 6:7-23. doi:10.1007/s11119-005-0681-8

Meisinger JJ, Schepers JS, Raun WR (2008) Crop nitrogen requirement and fertilization. In: Schepers JS, Raun WR (eds) Nitrogen in agricultural systems. Agronomy monograph 49. ASA, CSSA, SSSA, Madison, pp 563-612

National Agricultural Statistics Service (2013) New York crop and livestock report January 2013. USDA-NASS New York Field Office, Albany

Natural Resources Conservation Service (2013) Natural resources conservation service. Conservation practice standard: nutrient management. Code 590. NRCS, Washington

SAS Institute. (2012) Using JMP 10. Cary, NC

Schlegel AJ, Dhuyvetter KC, Havlin JL (1996) Economic and environmental impacts of long-term nitrogen and phosphorus fertilization. J Prod Ag 9:114-118. doi:10.2134/jpa1996.0114

Schulte EE, Hoskins B (1995) Recommended soil organic matter tests. In: Sims JT, Wolf A (eds) Recommended soil testing procedures for the northeastern United States. Bulletin 493, NEC-67, 3rd edn. University of Delaware, Newark, pp 63-74

Soil Survey Division Staff (1993) Soil survey manual. Soil conservation service. US. Department of Agriculture Handbook 18, Washington

Storer DA (1984) A simple high sample volume ashing procedure for determination of soil organic matter. Commun Soil Sci Plant Anal 15:759-772. doi:10.1080/00103628409367515

Vanotti MB, Bundy LG (1994) An alternative rationale for corn nitrogenfertilizer recommendations. J Prod Ag 7:243-249. doi:10.2134/ jpa1994.0243

Wolf A, Beegle DM (1995) Recommended soil tests for macronutrients: phosphorus potassium, calcium and magnesium. In: Sims JT, Wolf A (eds) Recommended soil testing procedures for the northeastern United States. Bulletin 493, NEC-67, 3rd edn. University of Delaware, Newark, pp 30-38

Wulforst JP, Phillips JA, Hanna WI, Puglia P, Crandall L (1974) Soil survey of Wyoming County, New York. US Government Printing Office, Washington 